\title{
Loss of Organochlorine Pesticide Residues during the Infusion Processes of Linden (Tilia cordata Mill.)
}

\author{
Celeste M. Lino* and Ma Irene N. Silveira \\ Laboratory of Bromatology and Hidrology, Faculty of Pharmacy, University of Coimbra, \\ 3000 Coimbra, Portugal
}

\begin{abstract}
Losses of residues of $\alpha$-hexachlorocyclohexane $(\alpha-\mathrm{HCH}), \beta-\mathrm{HCH}, \gamma-\mathrm{HCH}$, hexachlor obenzene (HCB), heptachlor and its epoxide, $p, p^{\prime}-D D E, p, p^{\prime}-D D D, o, p^{\prime}-D D T, p, p^{\prime}-D D T, \alpha$-endosulfan, $\beta$-endosulfan, endosulfan sulfate, aldrin, dieldrin, and endrin, when linden is subjected to three infusion processes, were studied. Compounds were quantified by gas-liquid chromatography with electron capture detection. Higher losses are found for heptachlor epoxide (HE) and o, $p^{\prime}$-DDT, in process 1 and for $\alpha-\mathrm{HCH}, \mathrm{HCB}, \mathrm{HE}$, and aldrin in procedures 2 and 3 . Lower losses are obtained for $\beta-\mathrm{HCH}$ in process 2. The best procedure for infusion preparation was procedure 3 .
\end{abstract}

Keywords: Pesticides; Tilia cordata Mill.; infusion processes

\section{INTRODUCTION}

Linden (Tilia cordata Mill.) is a medicinal plant that is widely used by the Portuguese population. Inflorescences and leaves are prepared by infusion. Calming and sedative effects, by oral ingestion, and softening and antipruriginous actions, by external use, are cited. Different types of pesticide residues may be present in medicinal plants. They are distinct between individual countries, but organochlorine pesticides still exist as pollutants in countries like Portugal, despite their prohibition 8 years ago (Decree 660/88).

As tea is submitted to an infusion process prior to human consumption, it is therefore important to evaluate the percentage loss of pesticide residues during this process. Some published papers described losses of organophosphorus and pyrethroids and only $\gamma-\mathrm{HCH}$ and DDT residues in black or green tea (Wan et al., 1991; Zongmao and Haibin, 1988) and also in Livesticum officinaleK and Tenacetum bal samita L. (Miellet, 1982). Other papers describe the determination of organochlorine pesticide residues in black tea (Peterson and J ensen, 1986) and in linden and in camomile (Fernández et al., 1993; Carisano and Rovida, 1995), but not in their infusions. In the present work, we intend to evaluate the loss of residues of insecticides like HCH isomers $(\alpha$, $\beta, \gamma)$, DDT group ( $\mathrm{p}^{\prime}, \mathrm{p}^{\prime}-$ and $\mathrm{o}, \mathrm{p}^{\prime}-\mathrm{DDT}, \mathrm{p}, \mathrm{p}^{\prime}-\mathrm{DDE}$, and $\left.\mathrm{p}, \mathrm{p}^{\prime}-\mathrm{DDD}\right)$, aldrin, dieldrin and endrin, heptachlor and its epoxide ( $\mathrm{HE})$, endosulfan $(\alpha, \beta$, and sulfate), and a fungicide, HCB, using three different processes of linden infusion preparation.

\section{EXPERIMENTAL PROCEDURES}

Reagents. Sodium sulfate, anhydrous granulated for residue analysis (Merck), and n-hexane and dichloromethane (Carlo Erba, I taly) were of pesticide residue grade; water was purified via Milli Q (Millipore, Bedford, MA); pesticide standards were obtained from Dr. Ehrenstorfer (West Germany); elution solvents, $\mathrm{n}$-hexane and dichloromethane-n-hexane (15 + 85), were prepared daily.

Materials and Apparatus. A gas-liquid chromatograph, Carlo Erba Mega HRGC 5300 equipped with a ${ }^{63} \mathrm{Ni}$ electron capture detector, was used. Two fused silica capillary columns,

* To whom correspondence should be addressed (fax 39-27126).

S0021-8561(96)00941-7 CCC: $\$ 14.00$
$30 \mathrm{~m} \times 0.25 \mathrm{~mm} \times 0.25 \mu \mathrm{m}$, with chemically bonded phases DB-5 and DB-17 (J \&W Scientific), were used. The first one was used for quantification and the second as a confirmation column. In both columns, $1 \mu \mathrm{L}$ of sample was injected in the splitless mode, and the splitter was opened after $60 \mathrm{~s}$. Chromatographic conditions were at temperatures of $280{ }^{\circ} \mathrm{C}$ for the detector, $220^{\circ} \mathrm{C}$ for the injector, and $150{ }^{\circ} \mathrm{C}$ held for 1 min and programmed at $10^{\circ} \mathrm{C} / \mathrm{min}$ to $210^{\circ} \mathrm{C}$ hel d for $1 \mathrm{~min}$ and programmed at $3{ }^{\circ} \mathrm{C} / \mathrm{min}$ to $230^{\circ} \mathrm{C}$, held for $5 \mathrm{~min}$ and finally programmed at $3{ }^{\circ} \mathrm{C} / \mathrm{min}$ to $250{ }^{\circ} \mathrm{C}$, held for $3 \mathrm{~min}$ to the first column and for $10 \mathrm{~min}$ to the second col umn. Gases used were as follows: carrier gas helium N60 carrier at $2 \mathrm{~mL}$ / mim, split valve $100 \mathrm{~mL} / \mathrm{min}$, purge valve $2 \mathrm{~mL} / \mathrm{min}$, makeup gas, nitrogen at $120 \mathrm{kPa}$. For quantification, a Spectra-Physics 4270 integrator was used, which compared peak areas in samples and standard solutions. A mechanical shaker for the separatory funnel, Agitelec (J . Toulemond, Paris), was used. The water bath was set to $\sim 35^{\circ} \mathrm{C}$. Other equipment was also used: nitrogen $U$ for extract concentration, vacuum system for SPE and vacuum pump B-160 Vacobox Büchi (Switzerland), centrifuge Pyrex test tubes with PTFE-lined screw caps from Schott (West Germany), pyriform flasks (50 mL), rotary vacuum evaporator (Heidolph VV 2001), and filter paper Whatman no. 4 (Maidstone, England) washed with acetone.

All Florisil glass cartridges $(6 \mathrm{~mL})(\mathrm{J}$. T. Baker, Phillipsburg, NJ ) were from the same lot. Linden samples composed by inflorescences and leaves were collected from open-field trees.

Sample Preparation. The process of drying was conducted in an oven at $40{ }^{\circ} \mathrm{C}$. The dry sample was cut into very small pieces with scissors, ground to a powder in a mortar with a pestle, and then homogenized.

Infusion Processes. Infusions were prepared with tap water, as in the usual process of infusion preparation, and the same kettle $(13.4 \times 13.8 \mathrm{~cm}$ i.d.) was used in all studies. Three different infusion processes were carried out. Each procedure was done in triplicate, using $2 \mathrm{~g}$ of linden. Process 1 : In the first, one $\mathrm{mL}$ of a pesticide standard mixture was added to linden in the same concentration used for recovery study. After being left to stand $15 \mathrm{~min}$, linden was placed in the kettle containing $200 \mathrm{~mL}$ of tap water. After the water boiled, it was allowed to stand for $3 \mathrm{~min}$. It was then cooled in a recipient containing ice-water. Process 2: The second procedure was similar, but instead of placing linden in the water, $200 \mathrm{~mL}$ of tap water was first boiled. After the kettle was turned off, spiked linden was added to the water and allowed to stand for $3 \mathrm{~min}$. It was cooled in a manner similar to that described in the previous procedure. Process 3: In the third process, the linden was placed in a $600 \mathrm{~mL}$ cup, and after addition of standard mixture and standing for $15 \mathrm{~min}, 200 \mathrm{~mL}$ of boiling tap water was added to it. It was allowed to stand for $3 \mathrm{~min}$ and cooled in ice-water. 
Table 1. Recovery Mean (CV) $(\%)(n=5)$ of 16 Organochlorine Pesticides from Linden Infusion

\begin{tabular}{lcc}
\hline \multicolumn{1}{c}{ compd } & $\begin{array}{c}\text { concn in linden } \\
\left(\mu \mathrm{gg}^{-1}\right)\end{array}$ & $\begin{array}{c}\text { mean } \\
(\mathrm{CV})(\%)\end{array}$ \\
\hline$\alpha-\mathrm{HCH}$ & 25 & $109(9)$ \\
$\mathrm{HCB}$ & 250 & $96(5)$ \\
$\beta$-HCH & 25 & $96(13)$ \\
$\gamma$-HCH & 75 & $91(13)$ \\
heptachlor & 125 & $82(18)$ \\
aldrin & 250 & $88(9)$ \\
heptachlor epoxide & 125 & $49(17)$ \\
$\alpha$-endosulfan & 50 & $88(4)$ \\
p,p'-DDE & 625 & $76(2)$ \\
dieldrin & 125 & $78(6)$ \\
endrin & 250 & $81(22)$ \\
$\beta$-endosulfan & 100 & $34(15)$ \\
p,p'-DDD & 625 & $83(8)$ \\
o,p'-DDT & 625 & $77(6)$ \\
endosulfan sulfate & 100 & $39(24)$ \\
p,p'-DDT & 625 & $81(6)$
\end{tabular}

To verify the effect of heat on a standard solution of organochlorine pesticide residues, $1 \mathrm{~mL}$ of that solution was added to $200 \mathrm{~mL}$ of tap water and heated in a similar procedure $\left(100{ }^{\circ} \mathrm{C}, 3 \mathrm{~min}\right)$.

Recovery Study. A linden infusion was prepared by adding the linden $(15 \mathrm{~g})$ to boiling water $(1500 \mathrm{~mL})$, providing the same proportion used for different infusion processes (200 $\mathrm{mL}$ of water $/ 2 \mathrm{~g}$ of linden), for $3 \mathrm{~min}$. It was cooled as in the previous description. It was filtered through paper. To evaluate the recovery of pesticide residues in this matrix, 1 $\mathrm{mL}$ of a standard solution (corresponding to $25 \mu \mathrm{g} / \mathrm{kg}$ of $\alpha-\mathrm{HCH}$ and to $625 \mu \mathrm{g} / \mathrm{kg}$ of DDT, isomers, and analogs) (Table 1 ) was added to $200 \mathrm{~mL}$ of linden tea over five replications. Two samples of $200 \mathrm{~mL}$ of linden tea were used like sample blanks. These samples were submitted to the whole procedure (extraction method and SPE cleanup). The results of the obtained recoveries and coefficients of variation are presented in Table 1.

Extraction Method. After filtration of thelinden infusion through paper and washing of the cake with water, the water extract was placed into a $500 \mathrm{~mL}$ separatory funnel containing $20 \mathrm{~mL}$ of $\mathrm{n}$-hexane. Then, the separatory funnel was shaken for $2 \mathrm{~min}$ and the $\mathrm{n}$-hexane phase passed through anhydrous sodium sulfate to $50 \mathrm{~mL}$ pyriform flasks. The aqueous phase was reextracted with $20 \mathrm{~mL}$ of $\mathrm{n}$-hexane. The $\mathrm{n}$-hexane phases were concentrated in a vacuum evaporator $\left(\sim 35^{\circ} \mathrm{C}\right)$ to $3 \mathrm{~mL}$.

SPE Cleanup. A similar SPE cleanup for $n$-hexane extracts of linden samples (Lino and Silveira, 1997) was used for the extraction of the linden infusion. It was made by adding $1 \mathrm{~cm}$ of sodium sulfate to a Florisil cartridge and washing the column with $10 \mathrm{~mL}$ of $\mathrm{n}$-hexane without letting the column dry. The concentrated n-hexane extract was transferred to the column. It was al lowed to flow by gravity. Two different eluents, $\mathrm{E}_{1}, 2 \times 5 \mathrm{~mL}$ of $\mathrm{n}$-hexane, $\mathrm{E}_{2}, 2 \times 5 \mathrm{~mL}$ of dichloromethane-n-hexane $(15+85)$, were used. The eluates were collected in a graduated centrifuge tube. The eluates were concentrated to $1 \mathrm{~mL}$ for quantification by $\mathrm{GC}-$ ECD.

\section{RESULTS AND DISCUSSION}

Figure 1 presents chromatograms obtained in the DB-5 column of a standard solution of organochlorine pesticides, of an organic extract of water containing organochlorine pesticides after boiling at $100{ }^{\circ} \mathrm{C}$ for 3 min, and of an organic extract of linden infusion made by procedure 3 .

The extraction was made with n-hexane, and the cleanup of the supernatants was conducted using Florisil cartridges for $n$-hexane extracts because of the abundance in pigments that can raise problems for HRGC-ECD detection (Lino and Silveira, 1997). Sample extracts containing the organochlorine pesticide resi-

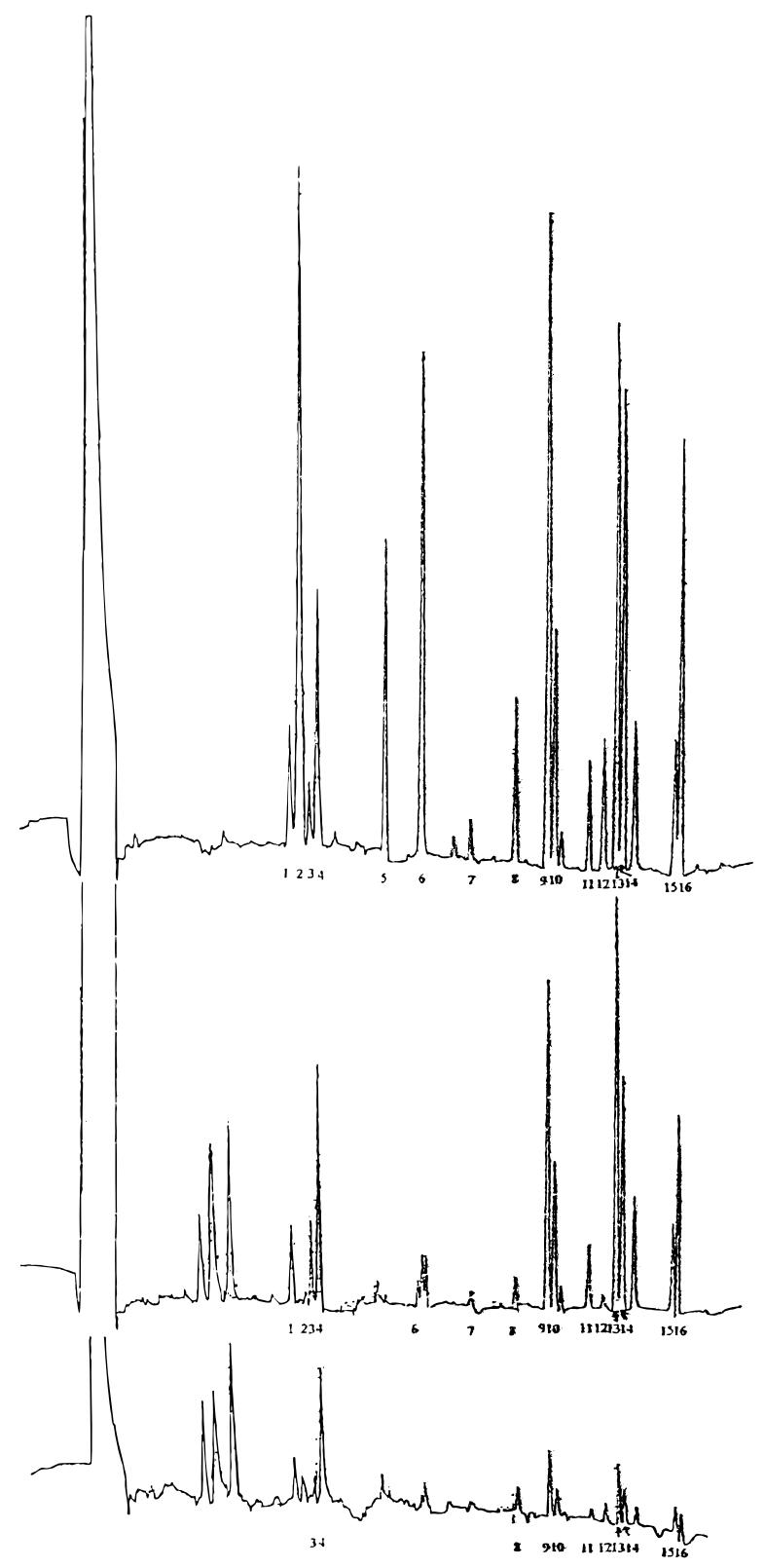

Figure 1. Typical chromatograms, on a DB-5 column, of organochlorine pesticides: (a) standard solution; (b) organic extract of water containing organochlorine pesticides after boiling at $100^{\circ} \mathrm{C}$ for $3 \mathrm{~min}$; (c) organic extract of linden infusion made by procedure 3 .

dues were analyzed on a GC system with DB-5 and DB17 columns. The first column separated the 16 compounds, and in the second column p, $p^{\prime}-$ DDD and o, $p^{\prime}-$ DDT coeluted.

The results of the recovery studies (Table 1) observed for linden tea are good for most compounds except for $\mathrm{HE}, \beta$-endosulfan, and endosulfan sulfate, for which recoveries are $49 \%, 34 \%$, and $39 \%$, respectively. Low recovery levels were also found in linden matrix for $\beta$-endosulfan (15\%), endosulfan sulfate (65\%), and $\mathrm{HE}$, which was not detected (Lino and Silveira, 1997).

The results of the infusion procedures $1-3$ are listed in Tables 2-4, respectively, and in Figures 2 and 3.

In infusion procedure 1 (Table 2) we can observe that between the $\mathrm{HCH}$ isomers, the $\beta$ presented lower losses, $48.90 \%$, and $\alpha-\mathrm{HCH}$ the higher percentage loss, $73.42 \%$. Heptachlor epoxide and o,p'-DDT remained on the linden. They were not present in the infusion. The percentage loss in this procedure is up to $90 \%$ for HCB, 
Table 2. Loss of OC Pesticide Residues Using Infusion Procedure 1

\begin{tabular}{|c|c|c|c|}
\hline compd & $\begin{array}{l}\text { concn in } \\
\text { linden } \\
\left(\mu \mathrm{g} \mathrm{kg}^{-1}\right)\end{array}$ & $\begin{array}{c}\text { concn in } \\
\text { linden infusion } \\
\left(\mu \mathrm{gg}^{-1}\right)\end{array}$ & $\%$ loss \\
\hline$\alpha-\mathrm{HCH}$ & 25 & 6.64 & 73.42 \\
\hline $\mathrm{HCB}$ & 250 & 6.95 & 97.23 \\
\hline$\beta-\mathrm{HCH}$ & 25 & 11.98 & 48.90 \\
\hline$\gamma-\mathrm{HCH}$ & 75 & 26.31 & 64.91 \\
\hline heptachlor & 125 & 12.42 & 90.04 \\
\hline aldrin & 250 & 11.95 & 95.22 \\
\hline heptachlor epoxide & 125 & nd & 100.00 \\
\hline$\alpha$-endosulfan & 50 & 10.85 & 78.30 \\
\hline$p, p^{\prime}-D D E$ & 625 & 31.72 & 94.04 \\
\hline dieldrin & 125 & 45.02 & 63.98 \\
\hline endrin & 250 & 32.47 & 87.01 \\
\hline$\beta$-endosulfan & 100 & 13.60 & 86.40 \\
\hline$p, p^{\prime}-D D D$ & 625 & 77.33 & 87.63 \\
\hline $0, p^{\prime}-D D T$ & 625 & nd & 100.00 \\
\hline endosulfan sulfate & 100 & 49.45 & 50.56 \\
\hline$p, p^{\prime}-D D T$ & 625 & 63.22 & 96.78 \\
\hline
\end{tabular}

Table 3. Loss of OC Pesticide Residues Using Infusion Procedure 2

\begin{tabular}{lccr}
\hline \multicolumn{1}{c}{ compd } & $\begin{array}{c}\text { concn in } \\
\text { linden } \\
\left(\mu \mathrm{kg}^{-1}\right)\end{array}$ & $\begin{array}{c}\text { concn in } \\
\text { linden infusion } \\
\left(\mu \mathrm{gg}^{-1}\right)\end{array}$ & \% loss \\
\hline$\alpha$-HCH & 25 & nd & 100.00 \\
$\mathrm{HCB}$ & 250 & nd & 100.00 \\
$\beta$-HCH & 25 & 23.66 & 5.37 \\
$\gamma$-HCH & 75 & 17.38 & 76.83 \\
heptachlor & 125 & nd & 100.00 \\
aldrin & 250 & nd & 100.00 \\
heptachlor epoxide & 125 & nd & 100.00 \\
$\alpha$-endosulfan & 50 & 31.36 & 37.28 \\
p,p'-DDE & 625 & 40.08 & 93.77 \\
dieldrin & 125 & 19.05 & 84.76 \\
endrin & 250 & 15.65 & 93.74 \\
$\beta$-endosulfan & 100 & 7.13 & 92.87 \\
p,p'-DDD & 625 & 33.52 & 92.79 \\
o,p'-DDT & 625 & nd & 100.00 \\
endosulfan sulfate & 100 & 16.06 & 83.94 \\
p,p'-DDT & 625 & 22.75 & 96.36
\end{tabular}

Table 4. Loss of OC Pesticide Residues Using Infusion Procedure 3

\begin{tabular}{|c|c|c|c|}
\hline compd & $\begin{array}{l}\text { concn in } \\
\text { linden } \\
\left(\mu \mathrm{gg}^{-1}\right)\end{array}$ & $\begin{array}{c}\text { concn in } \\
\text { linden infusion } \\
\left(\mu \mathrm{gg}^{-1}\right)\end{array}$ & $\%$ loss \\
\hline$\alpha-\mathrm{HCH}$ & 25 & nd & 100.00 \\
\hline $\mathrm{HCB}$ & 250 & nd & 100.00 \\
\hline$\beta-\mathrm{HCH}$ & 25 & 19.72 & 21.11 \\
\hline$\gamma-\mathrm{HCH}$ & 75 & 53.00 & 29.34 \\
\hline heptachlor & 125 & nd & 100.00 \\
\hline aldrin & 250 & nd & 100.00 \\
\hline heptachlor epoxide & 125 & nd & 100.00 \\
\hline$\alpha$-endosulfan & 50 & 7.37 & 85.26 \\
\hline$p, p^{\prime}-D D E$ & 625 & 31.59 & 94.95 \\
\hline dieldrin & 125 & 7.65 & 93.85 \\
\hline endrin & 250 & 15.13 & 92.60 \\
\hline$\beta$-endosulfan & 100 & 7.63 & 92.41 \\
\hline$p, p^{\prime}-D D D$ & 625 & 53.31 & 91.47 \\
\hline $0, p^{\prime}-D D T$ & 625 & 33.94 & 94.57 \\
\hline endosulfan sulfate & 100 & 10.82 & 89.18 \\
\hline$p, p^{\prime}-D D T$ & 625 & 56.60 & 90.95 \\
\hline
\end{tabular}

heptachlor, aldrin, $p, p^{\prime}-D D E$, and $p, p^{\prime}-D D T$. The percentage loss for $p, p^{\prime}-$ DDD was higher than $80 \%$. The same happened with endrin and $\beta$-endosulfan. Endosulfan sulfate presented the lowest percentage loss, $50.56 \%$.

The most elevated losses for the majority of the 16 compounds in the study were observed in procedures 2 and 3 (Tables 3 and 4), with the exception of the $\beta-\mathrm{HCH}$, which presented the lower percentage of losses, $21.11 \%$, in procedure 3 , and $5.37 \%$, in procedure 2 , despite its

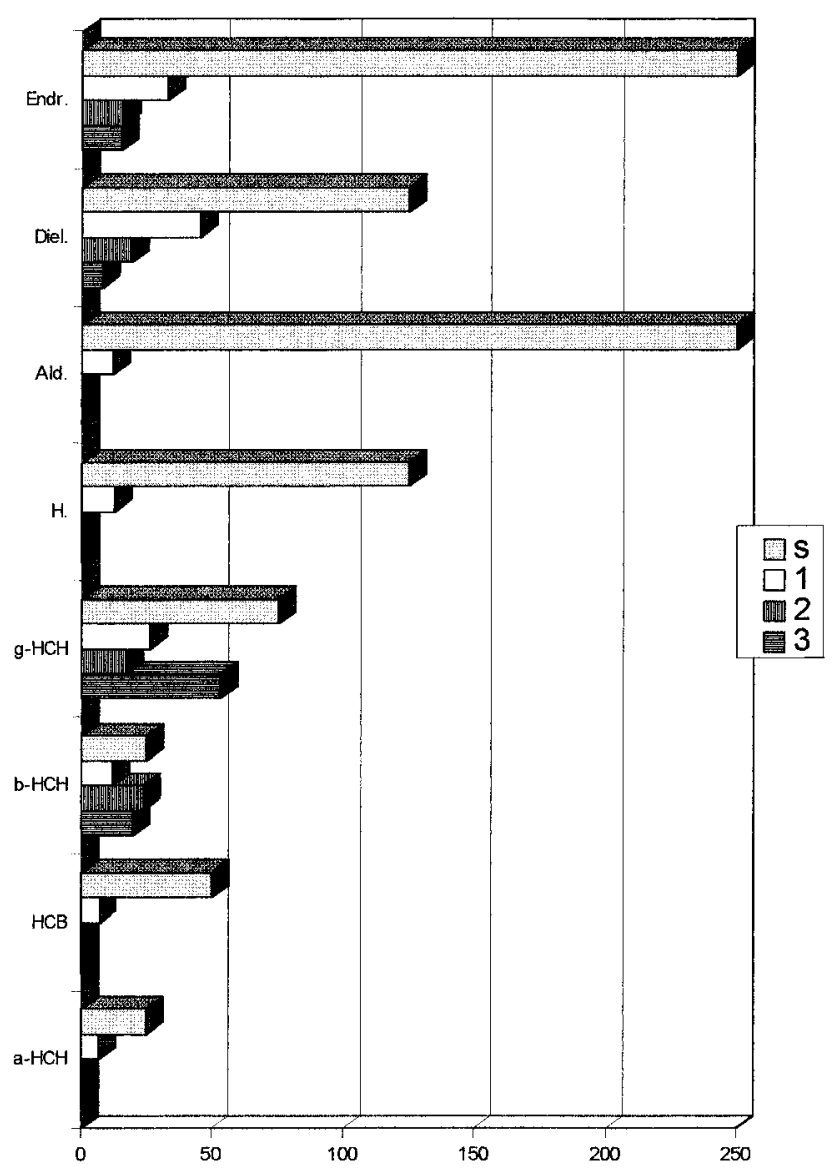

Figure 2. Graphic representation of organochlorine pesticide concentration in linden infusion $(\mu \mathrm{g} / \mathrm{kg})$ prepared by three different procedures: s, standard solution (top bar of each grouping); 1, procedure 1 (second bar of each grouping); 2, procedure 2 (third bar of each grouping); 3 , procedure 3 (bottom bar of each grouping).

lower water solubility in comparison with other $\mathrm{HCH}$ isomers (Table 6). That fact may be due to its lower fugacity and volatibility proportion (Suntio et al., 1988), which lead to the volatilization of $\alpha$ and $\gamma$ isomers when the infusion occurs. Also, $\gamma-\mathrm{HCH}$ is an exception because it presented less percentage losses in procedure 3, 29.34\%. Hexachlorobenzene was lost completely in procedures 2 and 3 and almost completely in procedure $1,97.23 \%$, which is according to their water solubility in spite of its lower fugacity. The loss of heptachlor epoxide was complete in all three of the infusion procedures. With respect to DDT isomers, losses of o, $p^{\prime}$ DDT in procedures 1 and 2 were complete and in procedure 3 were higher than $90 \%$. p, $p^{\prime}$-DDT losses were similar in the three studied procedures, higher than $90 \%$. p, $p^{\prime}$-DDD presented percentage losses that were lower with relation to DDE and $p, p^{\prime}$-DDT in the three studied procedures. This phenomena is in relation to its water solubilities (Table 6).

In procedure 3 , only $\beta$ - and $\gamma$ - $\mathrm{HCH}$ presented losses higher than $20 \%$ but lower than $30 \%$. Total losses occurred for $\alpha-\mathrm{HCH}, \mathrm{HCB}$, heptachlor, aldrin, and $\mathrm{HE}$. For the remaining compounds, the losses are higher than $85 \%$. More el evated losses occurred for the vast majority of the compounds in procedure 3 , followed closely by procedure 2 .

With procedure 2, lower losses were verified for $\beta$ - $\mathrm{HCH}$, with $5.37 \%$, followed by $\alpha$-endosulfan, $37.28 \%$, $\gamma-\mathrm{HCH}, 76.83 \%$, and endosulfan sulfate and dieldrin with $83.94 \%$ and $84.76 \%$, respectively. For the remain- 


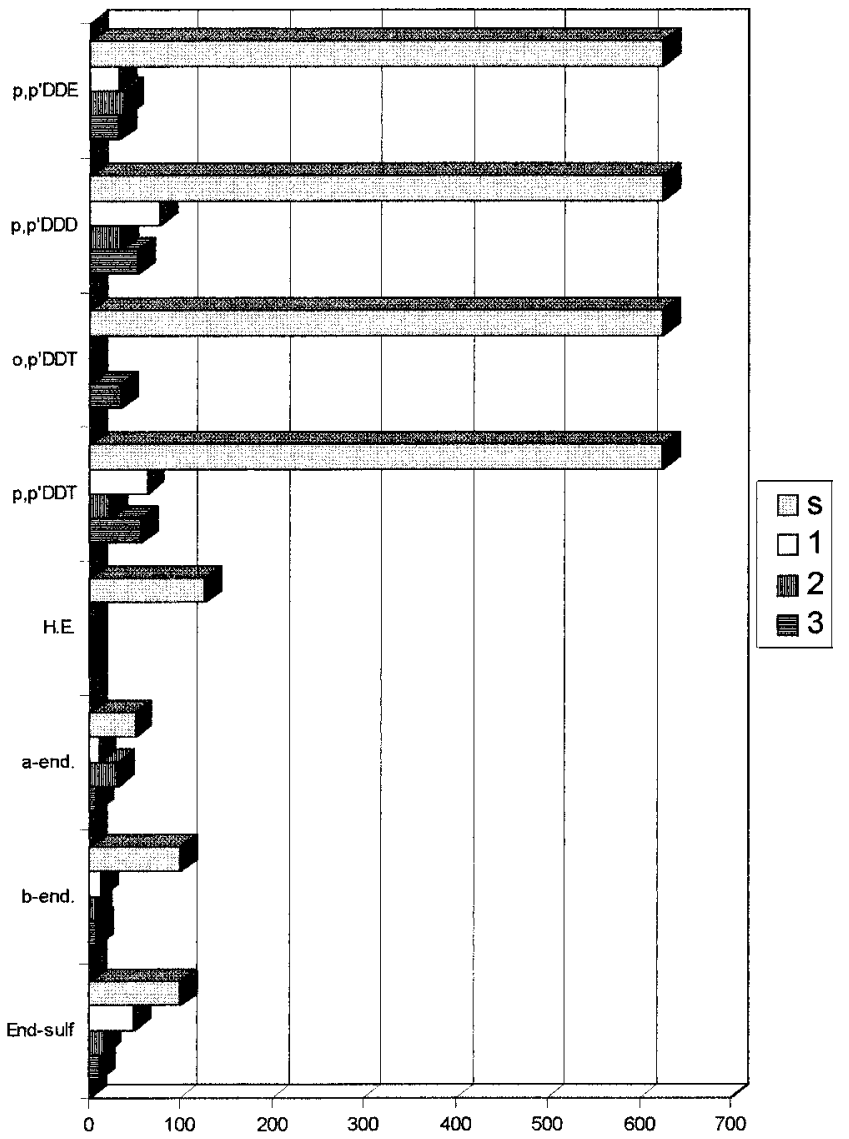

Figure 3. Graphic representation of organochlorine pesticide concentration in linden infusion $(\mu \mathrm{g} / \mathrm{kg})$ prepared by three different procedures: s, standard solution (top bar of each grouping); 1, procedure 1 (second bar of each grouping); 2, procedure 2 (third bar of each grouping); 3, procedure 3 (bottom bar of each grouping).

Table 5. Effect of Boiling $\left(100^{\circ} \mathrm{C}, 3 \mathrm{Min}\right)$ on Standard Solutions of Organochlorine Pesticide Residues

\begin{tabular}{|c|c|c|c|}
\hline compd & $\begin{array}{l}\text { concn in } \\
\text { linden } \\
\left(\mu \mathrm{g} \mathrm{kg}^{-1}\right)\end{array}$ & $\begin{array}{l}\text { concn in } \\
\text { linden infusion } \\
\left(\mu \mathrm{gg}^{-1}\right)\end{array}$ & $\%$ loss \\
\hline$\alpha-\mathrm{HCH}$ & 25 & 23.55 & 5.80 \\
\hline $\mathrm{HCB}$ & 250 & 2.95 & 98.82 \\
\hline$\beta-\mathrm{HCH}$ & 25 & 14.00 & 44.00 \\
\hline$\gamma-\mathrm{HCH}$ & 75 & 40.75 & 45.67 \\
\hline heptachlor & 125 & nd & 100.00 \\
\hline aldrin & 250 & 46.33 & 81.47 \\
\hline heptachlor epoxide & 125 & 37.83 & 69.73 \\
\hline$\alpha$-endosulfan & 50 & 10.50 & 79.00 \\
\hline$p, p^{\prime}-D D E$ & 625 & 207.67 & 66.77 \\
\hline dieldrin & 125 & 45.25 & 63.80 \\
\hline endrin & 250 & 131.17 & 47.53 \\
\hline$\beta$-endosulfan & 100 & 9.03 & 90.97 \\
\hline$p, p^{\prime}-D D D$ & 625 & 369.67 & 40.85 \\
\hline $0, p^{\prime}-D D T$ & 625 & 230.17 & 63.17 \\
\hline endosulfan sulfate & 100 & 67.00 & 33.00 \\
\hline$p, p^{\prime}-D D T$ & 625 & 287.83 & 53.95 \\
\hline
\end{tabular}

ing compounds, losses were up to $92.79 \%$, and six of the compounds were completely lost.

According to the obtained results, procedure 1 seems to us the least recommended method for infusion preparation of linden because it presents the lowest percentage loss of most organochlorine pesticide residues in the study (with the exception of $\beta$ - $\mathrm{HCH}$ in both procedures 2 and 3 ) and procedure 3 the most advised method due to the loss of compounds with the exception of $\gamma-\mathrm{HCH}$, whose losses are higher in procedures 2 and 1 .
Table 6. Water Solubility and Fugacity Ratio of Organochlorine Pesticides Involved in This Study (Suntio et al., 1988)

\begin{tabular}{|c|c|c|}
\hline compd & $\begin{array}{c}\text { water solubility } \\
\left(\mathrm{g} / \mathrm{m}^{3} \text { at } 20^{\circ} \mathrm{C}\right)\end{array}$ & $\begin{array}{l}\text { fugacity ratio } \\
\left(\mathrm{F} \text { at } 20^{\circ} \mathrm{C}\right)\end{array}$ \\
\hline$\alpha-\mathrm{HCH}$ & 1.0 & 0.041 \\
\hline $\mathrm{HCB}$ & 0.04 & 0.0075 \\
\hline$\beta-\mathrm{HCH}$ & 0.1 & 0.0012 \\
\hline$\gamma-\mathrm{HCH}$ & 6.5 & 0.12 \\
\hline heptachlor & 0.1 & 0.17 \\
\hline aldrin & 0.02 & 0.14 \\
\hline heptachlor epoxidec & & \\
\hline$\alpha$-endosulfana & 0.15 & 0.22 \\
\hline$p, p^{\prime}-D D E$ & 0.04 & 0.2 \\
\hline dieldrin & 0.17 & 0.026 \\
\hline endrin & 0.23 & 0.013 \\
\hline$\beta$-endosulfan ${ }^{a}$ & & \\
\hline $\begin{array}{l}p, p^{\prime}-D D D \\
o, p^{\prime}-D D T^{b}\end{array}$ & 0.05 & 0.12 \\
\hline endosulfan sulfate & & \\
\hline$p, p^{\prime}-D D T^{b}$ & 0.003 & 0.13 \\
\hline
\end{tabular}

The effect of boiling $\left(100{ }^{\circ} \mathrm{C}, 3 \mathrm{~min}\right)$ on standard solutions of organochl orine pesticide residues, observed in Table 5, shows us some el evated losses for heptachlor, $100 \%$, HCB, $98.82 \%$, $\beta$-endosulfan, $90.97 \%$, aldrin, $81.47 \%$, and $\alpha$-endosulfan, $79 \%$. Other compounds, like heptachlor epoxide, p,p'-DDE, dieldrin, and o, $p^{\prime}-D D T$, presented losses higher than $60 \%$ but lower than $70 \%$. With the exception of $\alpha-\mathrm{HCH}$, which presented losses of $5.8 \%$, the remaining compounds revealed losses comprising between $33 \%$ and $53.95 \%$.

Some investigators found an extraction rate of pesticide residues in water dependent on the water solubility. Their results indicate, for compounds like pyrethroids whose water solubility is lower than $1 \mathrm{mg} / \mathrm{kg}$, that the extraction rate in black tea is $1-4 \%$ (Wan et al., 1991). That factor conditions the percent of loss of pesticide residues much more than the effect of chemical degradation, which is not important. Also Zongmao and Haiben (1988) verify that the amount of extracted pesticide of green and black tea depends on the water solubility, and a very high concentration of some pesticide in tea may present a very low concentration in the tea infusion because of that parameter and of degradation caused by the high temperature. In their study, they also found a very low percentage of extracted DDT (1\%) and $\gamma-\mathrm{HCH}$ (6.5\%). Compounds like DDT, isomers and analogs, aldrin, and HCB have the lower water solubility (Table 6). Also, the fugacity ratio of $\mathrm{HCB}$ is very low, $0.0075 \mathrm{~F}$ (Table 6).

In this work, besides water solubility (Wan et al., 1991; Zongmao and Haiben, 1988; Nagayama, 1996) and fugacity ratio influence, the procedure of infusion preparation is determinant in the pesticide losses not only by the different contact forms but also because chemical degradation takes place when pesticides are submitted to the effect of boiling (Table 5), which is confirmed by Zongmao and Haiben (1988).

\section{LITERATURE CITED}

Carisano, A.; Rovida, C. SFE-facilitated Detection of Pesticide Residues in Camomile. LC-GC Int. 1995, 8, 334-337.

Decree 660/88, D.R. I Série No. 227, 4004, 30/9/88.

Fernández, N.; Sierra, M.; Garcia, J . J .; Diez, M. J .; Terán, M. T. Organochlorine Pesticide Residues in Black Tea, Camomile, and Linden. Bull. Environ. Contam. Toxicol. 1993, 50, 479-485. 
Lino, C. M.; Silveira, M. I. N. Extraction and Clean-up Methods for Determination of Organochlorine Pesticide Residues in Medicinal Plants. J . Chromatogr. A 1997, 769, 275-283.

Miellet, A. Dosage de Résidus de Pesticides par C.L.H.P. sur Plants Médicinales et Aromatiques (1). Ann. Fals. Expert. Chim. 1982, 75, 369-375.

Nagayama, T. Behavior of Residual Organophosphorus Pesticides in Foodstuffs During Leaching or Cooking. J . Agric. Food Chem. 1996, 44, 2388-2393.

Peterson, J . H.; J ensen, K. G. Pesticide Residues in Black Tea. Z. Lebensm.-Unters. Forsch. 1986, 182, 489-491.

Suntio, L. R.; Shiu, W. Y.; Mackay, D.; Seibes, J . N.; Glotfelty, D. Critical Review of Henry's Law Constants for Pesticides. Rev. Environ. Contam. Toxicol. 1988, 103, 1-59.

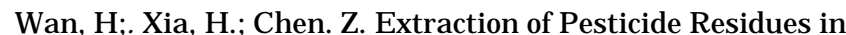
Tea by Water During the Infusion Process. Food Addit. Contam. 1991, 8, 497-500.

Zongmao, C.; Haibin, W. Factors Affecting Residues of Pesticides in Tea. Pestic. Sci. 1988, 23, 109-118.

Received for review December 11, 1996. Revised manuscript received March 24, 1997. Accepted April 4, $1997 .^{\otimes}$

J F9609410

${ }^{\otimes}$ Abstract published in Advance ACS Abstracts, J une 15, 1997. 